\title{
PENGARUH KEPUASAN KERJA DAN PEMELIHARAAN TERHADAP MOTIVASI PEGAWAI DI PERUM JASA TIRTA II SEKSI PATROL
}

\author{
Perum Jasa Tirta II Patrol Section \\ Riri Nur Fajriah, Fitria Damayanti \\ Manajemen FE Unwir \\ fitria.damayanti@unwir.ac.id
}

Effect Of Work Satisfaction And Maintenance Of Employee Motivation In

\begin{abstract}
ABSTRAK
Penelitian ini bertujuan untuk mengetahui pengaruh kepuasan kerja dan pemeliharaan terhadap motivasi pegawai di Perum Jasa Tirta II seksi Patrol. Metode penelititan yang digunakan adalah deskriptif asosiatif. Tempat penelitian di Perum Jasa Tirta II seksi Patrol. Data diperoleh dari kuesioner yang disebarkan kepada 32 responden.Kepuasan kerja di Perum Jasa Tirta II menurut indikator tingkat pekerjaan, umur, tingkat absensi, urnover, dan ukuran organisasi perusahaan. Diketahui gambaran kepuasan kerja dengan jumlah skor 1321 atau atau 82,5\% termasuk kategori sangat baik.Pemeliharaan di Perum Jasa Tirta II seksi Patrol menurut indikator mempertahankan kondisi fisik dan mental, meningkatkan kondisi fisik dan mental, kenyamanan kerja, kesejahteraan karyawan. Diketahui gambaran pemeliharaan dengan jumlah skor 1046 atau 65, 37\% termasuk kategori baik.

Motivasi Pegawai di Perum Jasa Tirta II seksi Patrol menurut inidkator dorongan, rekan kerja, perangsang, daya penggerak. Diketahui gambaran Motivasi Pegawai dengan jumlalh skor 1041 atau 65,06\% termasuk kategori baik.Koefisien Determinasi pada kepuasan kerja dan pemeliharan memberikan pengaruh terhadap motivasi pegawai di Perum Jasa Tirta II sebesar $81,72 \%$. Sedangkan sisanya $18,28 \%$ dipengaruhi oleh faktor-faktor lain yang tidak diteliti.Pengaruh kepuasan kerja dan pemeliharaan terhadap motivasi pegawai, koefisien korelasi berganda sebesar $\mathbf{r}=0,904$, yang berarti terdapat korelasi yang sangat kuat dan bernilai positif. Analisis regresi berganda.
\end{abstract}

Kata Kunci: Kepuasan Kerja, Pemeliharaan, Motivasi Pegawai.

\section{ABSTRACT}

This study aims to determine the effect of job satisfaction and maintenance on employee motivation in Perum Jasa Tirta II Patrol section. The research method used was associative descriptive. Research site in Perum Jasa Tirta II Patrol section. Data obtained from questionnaires distributed to 32 respondents.Job satisfaction in Perum Jasa Tirta II according to indicators of work level, age, absenteeism, turnover, and company organization size. Known job satisfaction figures with a total score of 1321 or $82.5 \%$ are included in the excellent category.

Maintenance in the Patrol Tirta II Public Corporation section according to indicators maintains physical and mental conditions, improves physical and mental conditions, job comfort, employee welfare. Known maintenance figures with a total score of 1046 or $65.37 \%$ are included in either category.Motivation of Employees in Patrol Services Tirta II Public Corporation according to encouragement, work colleagues, stimulants, driving force. It is known that the description of employee motivation with a total score of 1041 or $65.06 \%$ is in the good category. The coefficient of determination on job satisfaction and maintenance gives an influence on employee motivation at Perum Jasa Tirta II of $81.72 \%$. While the remaining $18.28 \%$ is influenced by other factors not examined.

The effect of job satisfaction and maintenance on employee motivation, the multiple correlation coefficient is $r=0.904$, which means there is a very strong and positive correlation. Multiple regression analysis

Keywords: job satisfaction, maintenance, employee motivation.

\section{PENDAHULUAN}

Kepuasan kerja seorang pegawai dapat memberikan dampak bagi hasil kerjanya. Kepuasan kerja dapat dilihat dari sikap karyawan terhadap pekerjaannya yang berhubungan dengan situasi kerja, kerjasama antar karyawan, imbalan yang diterima dalam kerja, dan hal-hal lain yang mencakup 
faktor fisik dan psikologis. Melihat kondisi tersebut tentunya pimpinan harus dapat membuat karyawan merasa dihargai dan merasa nyaman selama berada di tempat kerja serta memberikan fasilitas yang memadai untuk menunjang karyawan dalam mengerjakan pekerjaannya, agar kondisi kerja dapat lebih nyaman bagi karyawan..Salah satu caranya adalah dengan adanya pemeliharaan. Dengan adanya pemeliharan yang baik, tentunya pekerjaan yang dilaksanakan atau dibebankan kepada pegawai yang bersangkutan Akan menghasilkan sesuatu yang memang dikehendaki. Bermutu dan berkualitas bagi pimpinan, Dinas, organisasi, pemerintah, dan tentunya bagi masyarakat.Perusahaan harus memberikan motivasi kepada pegawai untuk dapat membantu pegawai dalam menjalankan tanggung jawabnya. Motivasi itu sendiri sebagai suatu hal untuk mendorong pegawai agar lebih bersemangat dan bekerja keras dalam mencapai hasil pekerjaan yang optimal. Untuk itu perlu dilakukan penelitian lebih lanjut mengenai kepuasan kerja, pemeliharaan dan motivasi pegawai

\section{Rumusan Masalah}

1. Bagaimana kepuasan kerja pada Perum Jasa Tirta II

2. Bagaimana pemeliharaan pada Perum Jasa Tirta II

3. Bagaimana motivasi pegawai pada Perum Jasa Tirta II
4. Bagaimana pengaruh kepuasan kerja terhadap motivasi pegawai di Perum Jasa Tirta II

5. Bagaimana pengaruh pemeliharaan terhadap motivasi pegawai di Perum Jasa Tirta II

6. Bagaimana pengaruh kepuasan kerja dan pemeliharaan terhadap motivasi pegawai di Perum Jasa Tirta I

Tujuan Penelitian

1. Untuk mengetahui kepuasan kerja pada Perum Jasa Tirta II

2. Untuk mengetahui pemeliharaan pada Perum Jasa Tirta II

3. Untuk mengetahui motivasi pada Perum Jasa Tirta II

4. Untuk mengetahui pengaruh kepuasan kerja terhadap motivasi pegawai pada Perum Jasa Tirta II

5. Untuk mengetahui pengaruh pemeliharaan terhadap motivasi pegawai pada Perum Jasa Tirta II

6. Untuk mengetahui pengaruh kepuasan kerja dan pemeliharaan terhadap motivasi pegawai pada Perum Jasa Tirta II.

\section{TINJAUAN PUSTAKA}

\section{Kepuasan Kerja}

Menurut Keith Davis dalam A. A. Anwar Prabu Mangkunegara (2013; 117), mengemukakan bahwa: "Job satisfaction is the favorableness or unfavorableness with employees view their work". (Kepuasan kerja adalah perasaan menyokong atau tidak 
menyokong yang dialami pegawai dalam bekerja).

Pendapat Wexley dan Yukl dalam A. A. Anwar Prabu Mangkunegara (2013; 117), mendefinisikan kepuasan kerja :"Is the way an employee feels about his or her job". (Adalah Cara pegawai merasakan dirinya atau pekerjaannya).

Sedangkan menurut Handoko dalam $\mathrm{H}$. Edy Sutrisno (2014; 75) mengemukakan: "Kepuasan kerja adalah keadaan emosional yang menyenangkan atau tidak menyenangkan bagi para karyawan memandang pekerjaan mereka”

Pegawai Akan merasa puas dalam bekerja apabila aspek-aspek pekerjaan dan aspek-aspek dirinya menyokong dan sebaliknya jika aspek-aspek tersebut tidak menyokong, pegawai Akan merasa tidak puas.

Pemeliharaan Sumber Daya Manusia

Menurut Malayu S.P. Hasibuan (2012; 179): "Pemeliharaan (maintenance) karyawan harus mendapat perhatian yang sungguh-sungguh dari manajer. Jika pemeliharaan karyawan kurang diperhatikan, semangat kerja, sikap, loyalitas karyawan Akan menurun. Absensi dan turnover meningkat, displin akan menurun, sehingga pengadaan, pengembangan, kompensasi, dan pengintegrasian yang telah dilakukan dengan baik dan biaya yang besar kurang berarti untuk menunjang tercapainya tujuan perusahaan”.
Edwin B. Flippo dalam Malayu S.P. Hasibuan (2012; 179): “The maintenance function of personnel is concerned primarily with preserving the physical, mental, and emotional condition of employees." (Fungsi pemeliharaan pegawai adalah menyangkut perlindungan kondisi fisik, mental, dan emosi karyawan).

Sedangkan menurut Suwatno (2013; 249): "Pemeliharan SDM merupakan usaha untuk membina dan mengembangkan kondisi fisik, mental, sikap dan perilaku karyawan agar karyawan menjadi loyal dan mampu bekerja dengan optimal sesuai dengan kebutuhan perusahaan. Kondisi tersebut maтри terwujud apabila ditunjang dengan kenyamanan kerja dan kesejahteraan karyawan yang memadai"

\section{Motivasi}

Menurut Sadili Samsudin $(2010 ; 281)$ : "Motivasi adalah proses mempengaruhi atau mendorong orang luar terhadap seseorang atau kelompok kerja agar mereka mau melaksanakan sesuatu yang telah ditetapkan."

Menurut Berelson dan Steiner dalam Danang Sunyoto $(2015 ; 192)$ mendefinisikan: "Motivasi adalah suatu usaha sadar untuk memengaruhi perilaku seseorang supaya mengarah tercapainya tujuan organisasi."

Menurut Malayu SP. Hasibuan dalam Danang Sunyoto (2015; 192): “Motivasi adalah perangsang keinginan (want) daya penggerak kemauan bekerja seseorang; 
setiap motif mempunyai tujuan tertentu yang ingin dicapai."

\section{Hubungan antar Variabel}

Hubungan Kepuasan Kerja terhadap Motivasi

Menurut Danang Sunyoto (2015:194): "Teori hierarkhi kebutuhan, kebutuhan dan kepuasan pekerja identik dengan kebutuhan biologis dan psikologis yaitu berupa material maupun non-material. Dasar teori ini adalah bahwa manusia merupakan makhluk yang keinginannya tak terbatas, alat motivasinya adalah kepuasan yang belum terpenuhi serta kebutuhanannya berjenjang"

Dari uraian diatas, dapat diketahui bahwa kepuasan kerja adalah salah satu Cara untuk meningkatkan motivasi kerja pegawai, sehingga motivasi yang diberikan dapat membuat pegawai bekerja lebih giat dan memberikan hasil yang terbaik untuk mencapai tujuan perusahaan.

\section{Hubungan Pemeliharaan Pegawai terhadap Motivasi}

Menurut Sadili Samsudin (2010; 282): "Beberapa faktor yang dapat mempengaruhi motivasi kerja, antara lain atasan, kolega, sarana fisik, kebijaksanaan, peraturan, imbalan jasa uang dan non uang, jenis pekerjaan, tantangan"

Dari uraian diatas, tentu saja pemeliharaan dapat menjadi motivasi bagi pegawai untuk mencapai suatu tujuan. Oleh karena itu, pemimpin harus memperhatikan kesejahteraan pegawai agar pegawai merasa di perhatikan dan dihargai.

\section{Hubungan Kepuasan Kerja dan}

\section{Pemeliharaan Pegawai terhadap Motivasi}

Menurut Danang Sunyoto (2015:199)

mengemukakan bahwa: "Tujuan pemberian motivasi antara lain mendorong gairah dan semangat kerja karyawan meningkatkan moral dan kepuasan kerja karyawan, meningkatkan produktivitas kerja karyawan, mempertahankan loyalitas dan kestabilan karyawan perusahaan, meningkatkan kedisiplinan dan menurunkan tingkat absensi karyawan, menciptakan suasa dan hubungan kerja yang baik, meningkatkan kreativitas dan partisipasi karyawan, meningkatkan kesejahteraan karyawan, mempertinggi rasa tanggung jawab karyawan terhadap tugastugasnya”

Dari uraian tersebut, penulis dapat menyimpulkan hubungan yang erat antara kepuasan kerja dan pemeliharan pegawai terhadap motivasi, karena kepuasan kerja dan pemeliharaan pegawai dapat mendorong pegawai untuk memiliki rasa tanggung jawab atas pekerjaannya dan juga loyal terhadap tempat bekerjanya.

\section{Kerangka Pemikiran}

Menurut Handoko dalam Edy Sutrisno (2014; 75) mengemukakan: “Kepuasan kerja adalah keadaan emosional yang menyenangkan atau tidak menyenangkan bagi para karyawan memandang pekerjaan mereka" 
Riri Nur Fajriah, Fitria Damayanti

Menurut Hasibuan dalam Danang Sunyoto: "Pemeliharaan adalah usaha mempertahankan dan atau meningkatkan kondisi fisik, mental, dan sikap karyawan agar mereka tetap loyal dan bekerja produktif untuk menunjang tercapainya tujuan perusahaan."

Menurut Sadili Samsudin (2010; 281): "Motivasi adalah proses mempengaruhi atau mendorong orang luar terhadap seseorang atau kelompok kerja agar mereka mau melaksanakan sesuatu yang telah ditetapkan."

\section{Hipotesis}

Dari uraian kerangka pemikiran diatas, maka dapat diajukan hipotesis sebagai berikut:

$\mathrm{H}_{1}$ : Diduga ada pengaruh variabel kepuasan kerja terhadap motivasi

$\mathrm{H}_{2}$ : Diduga ada pengaruh variabel pemeliharaan pegawai terhadap motivasi

$\mathrm{H}_{3}$ : Diduga ada pengaruh vaiabel kepuasan kerja dan pemeliharaan pegawai terhadap motivasi

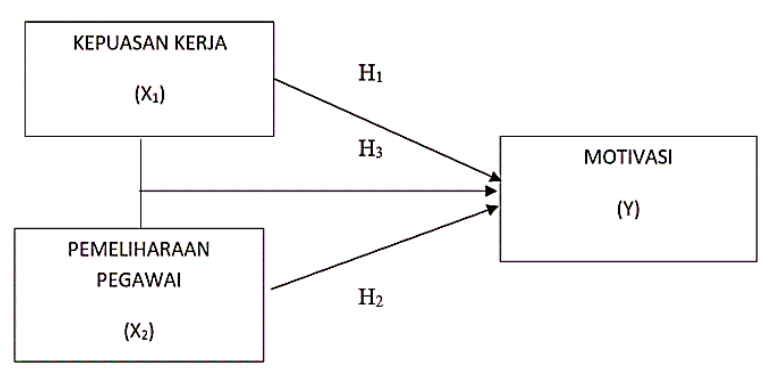

\section{METODOLOGI PENELITIAN}

Metode penelitian yang digunakan dalam penelitian ini adalah metode penelitian deskriptif dan asosiatif
Menurut Sugiyono (2011: 21) menyatakan bahwa: "Penelitian deskriptif merupakan penelitian yang bertujuan untuk memberikan gambaran terhadap obyek yang diteliti melalui data sampel atau populasi sebagaimana adanya”.

Metode penelitian deskriptif dalam penelitian ini untuk mengetahui gambaran tentang kepuasan kerja, pemeliharaan pegawai, dan motivasi di Perum Jasa Tirta II. Sedangkan metode penelitian asosiatif menurut Sugiyono (2013; 89), menyatakan bahwa: "Metode penelitian asosiatif adalah suatu pernyataan yang menunjukkan dugaan tentang hubungan antara dua variabel atau lebih".

Jadi, dengan menggunakan metode penelitian asosiatif bertujuan untuk mengetahui pengaruh kepuasan kerja, pemeliharaan pegawai, dan motivasi kerja di Perum Jasa Tirta II.

\section{Populasi dan Sampel}

Menurut Sugiyono (2012; 61) menyatakan bahwa: "Populasi adalah wilayah generalisasi yang tediriatas: obyek/subyek yang mempunyai kualitas dan karakteristik tertentu yang ditetapkan oleh peneliti untuk dipelajari dan kemudian ditarik kesimpulannya".

Populasi dalam penelitian ini adalah seluruh pegawai di Perum Jasa Tirta II Kantor Seksi Patrol yang berjumlah 47 orang.

$$
\text { Menurut Sugiyono (2012: }
$$
menyatakan bahwa: "Sampel adalah bagian 
dari jumlah dan karakteristik yang dimiliki oleh populasi. Bila populasi besar, dan peneliti tidak mungkin mempelajari seтиa yang ada pada populasi, misalnya karena keterbatasan Dana, tenaga dan waktu, maka peneliti dapat menggunakan sampel yang diambil dari populasi itu”.

Dikarenakan jumlah sampel yang besar, maka penelitian ini peneliti menggunakan teknik pengambilan sampel secara random sampling. Sugiyono (2012; 64) menyatakan bahwa, dikatakan simple (sederhana) karena pengambilan anggota sampel dari populasi secara acak tanpa memperhatikan strata yang ada dalam populasi itu.

Untuk menentukan besarnya sampel yang diambil, menurut Wiranata Sujarweni (2014; 66) ditentukan dengan rumus slovin, yaitu:

$$
\mathrm{n}=\frac{N}{1+\left(N x \theta^{2}\right.}
$$

Dimana:

$$
\begin{array}{ll}
\mathrm{N} & =\text { Populasi } \\
\mathrm{n} & =\text { Ukuran Sampel }
\end{array}
$$$$
\text { e }=\text { Presentasi kelonggaran }
$$$$
\text { ketidakterikatan karena kesalahan }
$$$$
\text { pengambilan sampel yang masih diinginkan }
$$$$
\mathrm{n}=\frac{47}{1+\left(47 x(10 \% 6)^{2}\right)}
$$$$
\mathrm{n}=\frac{47}{1+(47 x 0,01)}
$$$$
\mathrm{n}=\frac{47}{1+0,47}
$$$$
\mathrm{n}=\frac{47}{1,47}
$$$$
\mathrm{n}=31,97 \longrightarrow \text { digenapkan menjadi } 32
$$

Besarnya sampel yang diambil dalam penelitian ini adalah 32 orang.

\section{Operasinonal Variabel}

Sesuai dengan judul penelitian yang dipilih, yaitu Kepuasan Kerja (X1), Pemeliharaan Pegawai (X2), Motivasi (Y), maka variabel-variabel tersebut perlu didefinisikan secara operasional. Operasional variabel diperlukan untuk menjabarkan variabel penelitian ke dalam konsep dimensi dan indikator dengan tujuan untuk memudahkan dalam mendefinisikan dan menghindari perbedaan persepsi terhadap variabel penelitian.

\section{PEMBAHASAN}

\section{Uji Validitas dan Reliabilitas}

\section{Uji Validitas dan Reliabilitas Kepuasan}

\section{Kerja}

Item pertanyaan variabel kepuasan kerja terdiri atas 10 pertanyaan dan instrument penelitian diujikan pada 32 sampel. Hasilnya dapat dilihat pada lampiran. Untuk mengetahui validitas item nomor 1 dengan menggunakan rumus korelasi product moment person adalah:

$R_{x y}=$

$$
\begin{aligned}
& \frac{(32 \times 5358)(129 \times 1321)}{\sqrt{(32 \times 531)-(129)^{2}\left(32 \times 54965-(1321)^{2}\right.}} \\
& = \\
& \frac{171456-170409}{\sqrt{(16992-16641)-(1758880-1745041)}}
\end{aligned}
$$


$=\frac{1047}{2203,97}$

$=0,475$

Nilai ${ }^{r_{\text {tabel }}}$ dengan dk $=\mathrm{N}-1, \alpha=5 \%$ yaitu 0,355

Maka $r_{\text {hitung }}>r_{\text {tabel }}=0,475<0,355$

Jadi pertanyaan nomor 1 adalah Valid

Dengan menggunakan cara yang sama dapat diperoleh hasil tiap pertanyaan.

Uji Reliabilitas menggunakan rumus spearman brown (belah ganjil genap), hasil dapat dilihat pada lampiran. Adapun nilai $r$ diperoleh 0,662, kemudian dimasukan pada rumus spearman brown:

$r_{i}=\frac{2 r_{b}}{1+r_{b}}=\frac{2 x 0,662}{1+0,662}=\frac{1,324}{1,662}=0,798$

Hasil tersebut kemudian dibandingkan dengan $r_{\text {tabel }}$ pada signifikan $5 \%$ yaitu 0,355 , sehingga diketahui bahwa nilai $r_{i}$ lebih besar dari $r_{\text {tabel }}$. Jadi dapat disimpulkan bahwa instrument kepuasan kerja dinyatakan reliable.

\section{Uji Validitas dan Reliabilitas}

\section{Pemeliharaan}

Item pertanyaan variabel Pemeliharaan terdiri

atas 8 pertanyaan dan instrument penelitian diujikan pada 32 sampel. Hasilnya dapat dilihat pada lampiran. Untuk mengetahui validitas item nomor 1 dengan menggunakan rumus korelasi product moment person adalah:

$$
\begin{aligned}
& R_{x y}= \\
& \frac{N\left(\sum x y\right)-\left(\sum x \sum y\right)}{\sqrt{\left\{N\left(x^{2}-\left(\sum x\right)^{2}\right\}\right.}\left\{N\left(\sum y^{2}-\left(\sum y\right)^{2}\right\}\right.} \\
& =
\end{aligned}
$$

$$
\begin{aligned}
& \frac{(32 \times 4247)(129 \times 1046)}{\sqrt{(32 \times 531)-(129)^{2}\left(32 \times 34574-(1046)^{2}\right.}} \\
& = \\
& =\frac{970}{2073,75} \\
& =0,467
\end{aligned}
$$

Nilai ${ }^{r_{\text {tabel }}}$ dengan $\mathrm{dk}=\mathrm{N}-1, \alpha=5 \%$ yaitu 0,355

Maka $r_{\text {hitung }}>r_{\text {tabel }}=0,467<0,355$

Jadi pertanyaan nomor 1 adalah Valid

Dengan menggunakan cara yang sama dapat diperoleh hasil tiap pertanyaan.

Uji Reliabilitas menggunakan rumus spearman brown (belah ganjil genap), hasil dapat dilihat pada lampiran. Adapun nilai $r$ diperoleh 0,679 , kemudian dimasukan pada rumus spearman brown :

$$
r_{i}=\frac{2 r_{b}}{1+r_{b}}=\frac{2 x 0,679}{1+0,679}=\frac{1,358}{1,679}=0,808
$$

Hasil tersebut kemudian dibandingkan dengan $r_{\text {tabel }}$ pada signifikan $5 \%$ yaitu 0,355 , sehingga diketahui bahwa nilai $r_{i}$ lebih besar dari $r_{\text {tabel }}$. Jadi dapat disimpulkan bahwa instrument Pemeliharaan dinyatakan reliable.

\section{Uji Validitas dan Reliabilitas Motivasi}

\section{Pegawai}

Item pertanyaan variable Motivasi Pegawai terdiri atas 8 pertanyaan dan instrument penelitian diujikan pada 32 sampel. Hasilnya 
dapat dilihat pada lampiran. Untuk mengetahui validitas item nomor 1 dengan menggunakan rumus korelasi product moment person adalah :

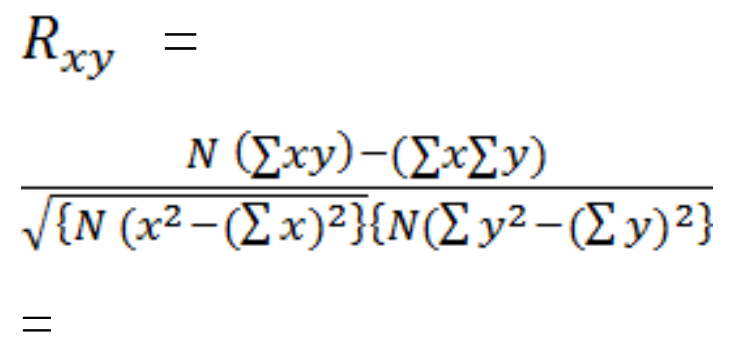

$$
\begin{aligned}
& \frac{(32 \times 4263)-(130 \times 1041)}{\sqrt{(32 \times 540)-(130)^{2}\left(32 \times 34271-(1041)^{2}\right.}} \\
& \quad=\frac{1086}{2221,84} \\
& \quad=0,488784 \\
& \text { Nilai } r_{\text {tabel }} \text { dengan dk }=\mathrm{N}-1, \alpha=5 \% \text { yaitu } 0,355 \\
& \text { Maka } r_{\text {hitung }}>r_{\text {tabel }}=0,488<0,355
\end{aligned}
$$

Jadi pertanyaan nomor 1 adalah Valid

Dengan menggunakan cara yang sama dapat diperoleh hasil tiap pertanyaan.

Uji Reliabilitas menggunakan rumus spearman brown (belah ganjil genap), hasil dapat dilihat pada lampiran. Adapun nilai $r$ diperoleh 0,639, kemudian dimasukan pada rumus spearman brown :

$r_{i}=\frac{2 r_{b}}{1+r_{b}}=\frac{2 x 0,639}{1+0,639}=\frac{1,278}{1,639}=0,779$

Hasil tersebut kemudian dibandingkan dengan $r_{\text {tabel }}$ pada signifikan $5 \%$ yaitu 0,355 , sehingga diketahui bahwa nilai $r_{i}$ lebih besar dari $r_{\text {tabel. }}$. Jadi dapat disimpulkan bahwa instrument Pemeliharaan dinyatakan

\begin{tabular}{|c|c|c|}
\hline No & Indikator & $\begin{array}{l}\text { Total } \\
\text { Skor }\end{array}$ \\
\hline 1 & $\begin{array}{l}\text { Tingkat Pekerjaan } \\
-129 \\
-127\end{array}$ & 256 \\
\hline 2 & $\begin{array}{l}\text { Umur } \\
-131 \\
-142\end{array}$ & 273 \\
\hline 3 & $\begin{array}{l}\text { Tingkat ketidakhadiran } \\
\text { (absen) kerja } \\
-123 \\
-129 \\
\end{array}$ & 252 \\
\hline 4 & $\begin{array}{l}\text { Turnover } \\
-129 \\
-133 \\
\end{array}$ & 262 \\
\hline 5 & $\begin{array}{l}\text { Ukuran organisasi } \\
\text { perusahaan } \\
-141 \\
-137 \\
\end{array}$ & 278 \\
\hline & Jumlah & 1321 \\
\hline
\end{tabular}
reliabel.

\section{Analisis Deskriptif}

Analisis Kepuasan Kerja

Total Skor Tanggapan Responden Terhadap Kepuasan Kerja

Berdasarkan tabel diatas, jumlah skor keseluruhan tanggapan responden variabel kepuasan kerja adalah:

$$
\frac{1321}{1600} \times 100=82,5 \%
$$

\begin{tabular}{|c|c|c|}
\hline No & Indikator & $\begin{array}{l}\text { Total } \\
\text { Skor }\end{array}$ \\
\hline 1 & $\begin{array}{ll}\text { Mempertahankan } & \text { Kondisi } \\
\text { Fisik } & \\
- & 129 \\
- & 127\end{array}$ & 256 \\
\hline 2 & $\begin{array}{l}\text { Meningkatkan Kondisi Mental } \\
-130 \\
-146\end{array}$ & 276 \\
\hline 3 & $\begin{array}{l}\text { Kenyamanan Kerja } \\
-\quad 123 \\
\end{array}$ & 252 \\
\hline
\end{tabular}

Dengan demikian responden menanggapi kepuasan kerja di Perum Jasa Tirta II seksi Patrol termasuk dalam kategori sangat puas.

\section{Analisis Pemeliharaan}

\section{Total Skor Tanggapan Responden} Terhadap Pemeliharaan 


\begin{tabular}{|l|l|l|}
\hline & -129 & \\
\hline 4 & Kesejahteraan Pegawai & 262 \\
& -129 & \\
& -133 & \\
\hline & Jumlah & 1046 \\
\hline
\end{tabular}

Berdasarkan tabel diatas, jumlah skor keseluruhan tanggapan responden variabel pemeliharaan adalah:

$$
\frac{1046}{1600} \times 100=65,375 \%
$$

Dengan demikian responden menanggapi pemeliharaan di Perum Jasa Tirta II seksi Patrol termasuk dalam kategori baik.

\section{Analisis Motivasi Pegawai}

al Skor Tanggapan Responden Terhadap Motivasi

\begin{tabular}{|l|l|l|}
\hline No & Indikator & $\begin{array}{l}\text { Total } \\
\text { Skor }\end{array}$ \\
\hline 1 & $\begin{array}{l}\text { Dorongan } \\
-130 \\
-126\end{array}$ & 256 \\
\hline 2 & $\begin{array}{l}\text { Rekan Kerja } \\
-133 \\
-138\end{array}$ & 271 \\
\hline 3 & $\begin{array}{l}\text { Perangsang } \\
-122 \\
-128\end{array}$ & \\
\hline 4 & $\begin{array}{l}\text { Daya Penggerak } \\
-130 \\
-134\end{array}$ & 250 \\
\hline & Jumlah & 264 \\
\hline
\end{tabular}

Berdasarkan tabel diatas, jumlah skor keseluruhan tanggapan responden variabel kepuasan kerja adalah:

$$
\frac{1041}{1600} \times 100=65,062 \%
$$

Dengan demikian responden menanggapi pemeliharaan di Perum Jasa Tirta II seksi Patrol termasuk dalam kategori sering.

\section{Analisis Asosiatif}

\section{Uji Normalitas}

Untuk menguji kenormalan distribusi sampel yang dilakukan pada penelitian ini agar dapat dipertanggungjawabkan dan digunakan analisis yang tepat maka dilakukan uji normalitas terhadap data sampel yang diperoleh dri kepuasan kerja, diuji dengan menggunakan metode Chi Kuadrat, sebagai berikut

a. Variabel X1 (Kepuasan Kerja)

Karena harga chi kuadrat hitung $(33,363)>$ chi kuadrat tabel $(11,070)$. Maka distribusi sampel yang dilakukan tidak normal.

b. Variabel X2 (Pemeliharaan)

Karena harga chi kuadrat hitung $(16,522)>$ chi kuadrat tabel $(11,070)$. Maka distribusi sampel yang dilakukan tidak normal.

c. Variabel Y (Motivasi)

Karena harga chi kuadrat hitung $(43,431)>$ chi kuadrat tabel $(11,070)$. Maka distribusi sampel yang dilakukan tidak normal.

\section{Analisis Koefisien Korelasi Berganda}

Korelasi ganda merupakan angka yang menunjukkan arah dan kuatnya hubungan antara dua variabel independen secara bersama-sama atau lebih dari satu variabel dependen. Jadi analisis korelasi ganda bertujuan untuk mengetahui koefisien korelasi antara variabel kepuasan kerja (X1) dan Pemeliharaan (X2) terhadapa Motivasi Pegawai (Y) secara simultan atau bersamasama: 
$R_{y} \cdot \mathrm{x} 1 \times 2=$

$$
\begin{aligned}
& \sqrt{\frac{r_{y x 1^{2}+r_{x y 2^{2}}-2 r_{x y 1} r_{y x 2} r_{x 1 x 2}}}{1-r_{x 1 x 2^{2}}}} \\
& R_{y} . \mathrm{1} 1 \times 2=
\end{aligned}
$$

$$
\sqrt{\frac{(0,95)^{2}+(0,054)^{2}-2(0,95)(0,054) \cdot(0,01)}{1-(0,01)^{2}}}
$$

$R_{y} \cdot \times 1 \times 2=$

$$
\begin{gathered}
\sqrt{\frac{(0,9025+0,002916)-(1,9)(0,00054)}{1-0,0001}} \\
R_{y} \times 1 \times 2=\sqrt{\frac{0,905416-0,001026}{0,9999}} \\
R_{y} \cdot \mathrm{x} 1 \times 2=\sqrt{\frac{0,90439}{0,9999}} \\
R_{y} \cdot \mathrm{x} 1 \times 2=0,904
\end{gathered}
$$

Dari perhitungan korelasi diatas diperoleh koefisien korelasi sebesar 0,904. Dapat disimpulkan bahwa pengaruh kepuasan kerja dan pemeliharaan terhadap motivasi pegawai termasuk dalam kategori sangat kuat.

\section{Analisis Koefisien Determinasi}

Koefisien determinasi merupakan suatu ukuran yang menunjukkan besar sumbangan dari variabel penjelas terhadap variabel respon. Dengan kata lain, koefisien determinasi menunjukkan variasi naik turunnya $\mathrm{Y}$ yang diterangkan oleh pengaruh liner $\mathrm{X}$.

\section{Analisis Koefisien Determinasi Kepuasan} Kerja dan Pemeliharaan terhadap Motivasi Pegawai

Untuk mengetahui seberapa besar kontribusi kepuasan kerja dan pemeliharaan terhadap motivasi pegawai, maka digunakan rumus koefisien determinasi sebagai berikut:

$\mathrm{Kd}=r^{2} \times 100 \%$

$\mathrm{Kd}=(0,904)^{2} \times 100 \%$

$\mathrm{Kd}=0.817216 \times 100 \%$

$\mathrm{Kd}=81,72 \%$

Artinya kepuasan kerja dan pemeliharan memberikan pengaruh terhadap motivasi pegawai di Perum Jasa Tirta II sebesar $81,72 \%$. Sedangkan sisanya $18,28 \%$ dipengaruhi oleh faktor-faktor lain yang tidak diteliti.

\section{KESIMPULAN}

Kondisi kepuasan kerja di Perum Jasa Tirta II sangat baik, hal ini dapat dilihat dari skor jawaban responden untuk yang diperoleh dari masing-masing indikator sebesar 1321 atau $82,5 \%$ termasuk kategori sangat baik.Kondisi pemeliharaan di Perum Jasa Tirta II sudah baik, hal ini dapat dilihat dari skor jawaban responden untuk yang diperoleh dari masingmasing indikator sebesar 1046 atau 65,37\% termasuk kategori baik.Kondisi motivasi di Perum Jasa Tirta II sudah baik, hal ini dapat dilihat dari skor jawaban responden untuk yang diperoleh dari masing-masing indikator sebesar 1041 atau 65,06\% termasuk kategori baik.Pengaruh kepuasan kerja dan pemeliharaan terhadap motivasi pegawai diperoleh dari koefisien korelasi berganda sebesar $r=0,904$ yang berarti terdapat korelasi yang sangat kuat. 


\section{DAFTAR PUSTAKA}

Samsudin, Sadili. 2010. Manajemen Sumber

Daya Manusia. Bandung. Pustaka Setia Hasibuan, Malayu. 2012. Manajemen

Sumber Daya Manusia. Jakarta. Bumi

Aksara

Sutrisno, Edy. 2014. Manajemen Sumber

Daya Manusia. Jakarta. Kencana

Suwatno. 2013. Manajemen SDM dalam

organisasi publik dan bisnis. Bandung.

Alfabeta.

Sunyoto, Danang. 2015. Manajemen dan

pengembangan sumber daya manusia.

Jakarta. CAPS

Sugiyono. 2012. Statistik untuk penelitian.

Bandung. Alfabeta.

Sedarmayanti. 2014. Manajemen Sumber

Daya Manusia, reformasi birokrasi, dan

manajemen negeri sipil. Bandung.

Refika Aditama

A A. Anwar Prabu Mangkunegara, Drs.,

M.Si. Psi.2011. Manajemen Sumber

Daya Manusia Perusahaan. PT. Remaja

Rosdakarya. Bandung

V. Wiratna Sujarweni. 2014. Metodologi

Penelitian, Yogyakarta: Pustaka Baru

Press. 